\title{
A Combination of Manual Therapy, Movement Systems, and Biopsychosocial Approaches for the Treatment of Upper Limb Adverse Neural Tissue Tension: A Case Report
}

\author{
Courtney A. Shinost ${ }^{1}$, Lucas E. Pratt ${ }^{2,3,4}$, Kayla Smith ${ }^{3}$ \\ ${ }^{1}$ Concentra Physical Therapy, San Marcos, CA, USA \\ ${ }^{2}$ Concentra Physical Therapy, San Diego, CA, USA \\ ${ }^{3}$ University of St. Augustine for Health Sciences, San Marcos, CA, USA \\ ${ }^{4}$ The Manual Therapy Institute, Park City, UT, USA \\ Email: Courtney.ShinostDPT@gmail.com
}

How to cite this paper: Shinost, C.A., Pratt, L.E. and Smith, K. (2017) A Combination of Manual Therapy, Movement Systems, and Biopsychosocial Approaches for the Treatment of Upper Limb Adverse Neural Tissue Tension: A Case Report. Open Access Library Journal, 4: e3669.

https://doi.org/10.4236/oalib.1103669

Received: May 15, 2017

Accepted: June 20, 2017

Published: June 23, 2017

Copyright $\odot 2017$ by authors and Open Access Library Inc.

This work is licensed under the Creative Commons Attribution International License (CC BY 4.0).

http://creativecommons.org/licenses/by/4.0/

\begin{abstract}
Background and Purpose: Peripheral nerve injuries can result from a multitude of causes including trauma, poor posture, and altered movement patterns. Adverse neural tension is a possible consequence to insult to the nervous system which can lead to dysfunction and fear avoidance behaviors. The purpose of this case report is to demonstrate the use of a multimodal approach in the physical therapy treatment of a patient who sustained an occupational upper extremity injury which resulted in adverse neural tissue tension of multiple peripheral nerves. Case Description: The patient was a 40year-old female who sustained an injury to the second right metacarpophalangeal joint. Impairments included joint hypomobility, decreased muscle function, and movement system dysfunction. The patient was treated six times over a two-week period. Intervention: The physical therapy treatment administered to the patient included manual therapy, exercises focused on improving movement systems impairment, exercise focused on improving neural excursion, and patient education based on the biopsychosocial model. The treatments were focused on improving function of work-related activities to decrease disability to promote regular and full job duties. Outcomes: Outcome measures include the Numeric Pain Rating Scale (NPRS), Fear Avoidance Beliefs Questionnaire of Work and Physical Activity (FABQ-W and FABQ-PA, respectively), and the Quick Disability of the Arm, Shoulder and Hand (QuickDASH). After six visits there was an NPRS rating of $0 / 10$ with rest and activity; the FABQ-W improved from 17/42 to 10/42; the FABQ-PA improved from $15 / 24$ to $3 / 24$; the QuickDASH improved from $22 \%$ symptom
\end{abstract}


related disability to $9 \%$ and improved from $75 \%$ disability with work-related tasked to $0 \%$ disability. Discussion: Interventions of joints mobilization, neuromuscular reeducation using the movement systems approach, and concepts focused on the biopsychosocial approach were determined to be an integral combination in the patient's successful return to full work-related duties.

\section{Subject Areas}

Clinical Trials

\section{Keywords}

Physical Therapy, Adverse Neural Tissue Tension, Biopsychosocial Model, Manual Therapy, Movement Systems

\section{Introduction}

Each year an estimated five million people in the United States will sustain a work-related injury [1]. Upper extremity disorders associated with work-related injuries typically result in a higher disability to the employee and a higher expense for the employer [1]. Upper extremity injuries primarily come in the form of bone fractures, lacerations, and joint dislocations with a lesser incidence of nerve involvement [1] [2]. Peripheral nerve injuries occur due to a multitude of causes. An individual's posture, movement patterns, and daily activities can contribute to a peripheral nerve damage [2] [3]. Trauma is one of the most prevalent causes of peripheral nerve injury and subsequent nerve sensitization [2] [3]. The Radial Nerve is the most common upper extremity peripheral nerve to be affected due to trauma, followed by the Ulnar Nerve, then the Median Nerve [2]. A sensitized nerve may have an abnormal response to a stimulus due to the hyperexcitability of the nerve [3]. Areas of the nerve expressing an increase in afferent discharge, or abnormal impulse generating sites (AIGS), can heighten the individual's perception of pain [3].

An example of prolonged hypersensitivity in the peripheral nerve leading to chronic pain is complex regional pain syndrome (CRPS) which is described as a decrease in function and an increase in pain that is not proportionate to the mechanism of injury [4]. The injury to the peripheral nerve or surrounding soft tissue may become sensitized and manifest as motor and sensory changes as well as trophic changes and edema in the distal aspect of the limb [5]. Prolonged sensitization of the nerve further leads to chemical changes in both the peripheral nerve and central nervous system (CNS) leading to central sensitization [5]. Central sensitization may also be a result of an adverse relationship between the nervous system and the immune system [5]. Central sensitization is condition of the CNS resulting in high reactivity of the peripheral nerves and disproportional pain perceptions.

Clinically physical therapists will typically see patient with CRPS as a result of 
an injury to an extremity [4]. In the physical therapy setting, it is therefore important to decrease irritation and prevent sensitization of peripheral nerves [6]. More common presentations of sensitization of the peripheral nerve are demonstrated with carpal tunnel syndrome (CTS) and lateral epicondyalgia [6]. A prolonged period of peripheral sensitization due to the hyperexcitability of the nerve may again result in chemical changes of the CNS leading to chronic pain [6]. Chronic pain has been associated with decreased function and as well as decreased rate of returning to work or regular activities of daily living [4] [6]. Chronic pain may lead to the development of a movement disorder from lack of use as well as negatively affect the immune system and self-identity [4] [5] [6]. [7].

Nerves are structures that are continuous physically, electrically, and chemically. The nervous system is a continuum of tissues that slide, glide, and move within the axial and appendicular skeleton [8]. A disruption of this continuum due to a lesion or mobility restriction may result in the patient's perceived pain [8]. Injury to nerves can result from a variety of causes such as trauma, compression, and traction which can mimic symptoms from more familiar musculoskeletal sources such as a tendinopathy or joint or soft tissue insult [3]. Neuropathic pain leading to adverse neural tissue tension can be brought on by a multitude of factors including, but not limited to, trauma, joint position or malalignment, and posture [3] [8]. A continuous stimulation of the nociceptors in a peripheral nerve can result in hypersensitivity of that nerve [6]. This hypersensitivity can then lead to AIGS which may result in an altered perception of pain in the form of allodynia, or central sensitization [3] [6]. Central sensitization is associated with chemical changes in the central nervous system that may lead to chronic pain [6].

The peripheral nerve, when moving properly, has a harmonious relationship with the fascial sheath surrounding the nerve [9]. The disruption of the harmonious synergy between the nerve and the fascia may limit the "neural excursion" of the peripheral nerve during movement [3] [8] [9]. When nerve roots or peripheral nerves are injured by an increase in mechanical stress that is greater than normal daily activities, the patient may present with what appears to be pain due to a musculoskeletal injury [3]. However, the patient's pain may actually be due to an irritation of the peripheral nerve causing neuropathic pain disguised as musculoskeletal pain [3]. Abnormal tension, compression, or excursion due to fascial restrictions may result in adverse neural tissue tension [3]. The presentation of adverse neural tissue tension with altered sensory and motor innervation in the form of hypersensitivity and muscle weakness, respectively, are indications for the utilization of upper limb neural tissue tension testing (ULTT) [3] [8].

ULTTs were first described by Butler and were used in the diagnosis of meningitis [10]. It was later found that ULTTs provide information related to the excursion of peripheral nerves [10]. Later still, it was found that many components of upper limbs can contribute to limited neural excursion which resulted 
in the use of ULTTs in the clinical setting [10]. Sites that render nerves vulnerable to injury are locations where the nerve braches, surfaces that are unyielding to movement, areas of fibro-osseous and soft tissue tunnels, and areas in the body where nerves are superficial [9]. Abnormal joint position during poor static postures and dysfunctional movement may contribute to the increase or decrease of the neurodynamics of the peripheral nerve [3]. Neurodynamics is the assessment of the mobility and length of a peripheral nerve [3]. Increased joint movement or lack of joint movement can affect the neurodynamics of the peripheral nerve [11].

Manual therapy including joint mobilization has been shown to be an effective treatment for reducing neural tension as evidenced by decreased peripheral symptoms [12]. Spinal joint manipulation, including a Grade V high-velocity low-amplitude (HVLA) thrust technique, has been shown to improve the joint mobility in the cervical spine and further reduce symptoms of neural tension [12] [13]. Mobilization of the spine at specific levels, namely C6, T6, and L4 have been shown to decrease the neural tension in the periphery [9]. Chu et al. found that Grade V manipulations can stimulate the sympathetic nervous system in both cervical symptomatic and asymptomatic individuals [12]. Theoretically, this type of manipulation stimulates the mechanoreceptors in the joint resulting in pain inhibition [12] [13] [14] [15]. In another study by Fernandez, the manipulation of the cervicothoracic junction was shown to improve movement in the cervical spine and decrease pain sensation during palpation [13]. Peripheral joint manipulation has also been shown to decrease neural pain perception [12] [13]. [14] [16]. Specific to the manipulation of the upper extremity, the Mills manipulation, which involves a HVLA thrust to the radiohumeral joint, intended to reduce the neural tension of the radial nerve, has been shown to decrease the presence of lateral elbow pain or pain in the distal deep radial nerve distribution of the forearm [16].

Observation of the patient's resting posture may also implicate adverse neural tissue tension. Postural assessment of a patient with upper extremity adverse neural tissue tension may present with the patient's cervical spine held in lateral flexion and rotation to the ipsilateral side [8]. The patient may also present with the upper extremity postured in shoulder abduction and internal rotation [8]. Depending on which peripheral nerve is responsible for producing symptoms, the patient may attain a position of elbow flexion or extension, forearm pronation or supination, or wrist flexion or extension. Ultimately, the patient demonstrates a posture which results in a slackening of the peripheral nerve at fault [8]

Movement patterns may contribute to the suspicion of neural tension of the upper extremity and due to slackening the nerve in the resting posture [9]. Specific movement patterns are characterized into movement system syndromes as described by Sahrmann, et al. [17] [18]. This movement system approach allows a physical therapist to assess a patient's dysfunction by classifying movements according to the direction which elicits pain, or chief complaints, and the impairment of the movements [18]. The movement systems approach is focused on 
correcting the movement impairment and malalignment contributing to the patient's symptoms [18]. Faulty static postures over a period of time can create dysfunction which leads to predictable patterns of movement and predictable areas of weakness and joint dysfunction [18]. The significance of the movement systems approach is to allow the physical therapist to recognize predictable patterns of movement that may be inhibiting function of the patient and resulting in pain [17] [18].

Another important consideration is the biopsychosocial approach to both the examination and the treatment of the patient. The biopsychosocial model is an approach that incorporates not only the physical cause of the patient's pain but also the emotional and social contributions which includes explaining the patient's dysfunction in terms the patient can understand with the intent to ease potential fear and anxiety associated with the dysfunction [19]. Once the patient is able to understand the reason for dysfunction or pain, it is theorized that the patient will become empowered [19] [20]. Allowing the patient to ask questions about the expected prognosis and possible sequelae of the dysfunction may empower the patient to have a better understanding of the current condition [20] However, patient education should focus on the pathoanatomical cause of pain [21]. Patient education should be based upon the understanding of anatomy and an explanation of perceived pain [21]. Arguably the most important aspect of the biopsychosocial model is the patient's responsibility with the rehabilitation process. It is theorized that once the patient is aware of his or her deficits due to the dysfunction, the patient will be more apt to participate in the rehabilitation process in terms of internal motivation, participation in the home exercise, and effort during physical therapy sessions [19] [20]. Decreasing fear avoidance and increasing involvement in activity is suggested to improve the patient's prognosis [21].

Often when individuals are experiencing pain due to dysfunction there is an attempt to avoid the stimulus that results in pain. Research has suggested that the avoidance of the painful stimulus may cause more disability than the pain [22]. The avoidance of the painful stimulus can be described as fear avoidance beliefs (FAB) and are commonly measured in outpatient orthopaedics by the use of the Fear Avoidance Beliefs Questionnaire (FABQ) as a standardized outcome measure. The FABQ is divided into two subscales that capture the FAB of work related tasks (FABQ-W) and the FAB related to physical activity (FABQ-PA). The FABQ has been used to measure FAB in workers' compensation patients and has shown to be both valid and reliable for patients with low back and cervical pain [22] [23]. In 2012 Inrig et al. researched the validity of the FABQ-W and FABQ-PA for patients with upper extremity injuries related to workers' compensation and found moderate to good correlations [22].

In addition to $\mathrm{FAB}$, patients with upper extremity injuries commonly experience disability due to their injury. The Disability of the Arm Shoulder and Hand (DASH) is an outcome measure used to assess the disability of the upper extremity associated with injury [24]. The QuickDASH is a shorter version of 
the DASH that only uses an eleven item questionnaire to determine the disability of the upper extremity compared to the DASH that is a twenty-one item questionnaire which has been shown to be a reliable and valid outcome measure for determining upper extremity disability [25].

The purpose of this case report is to demonstrate the beneficial use of manual therapy, movement system analysis and interventions, and biopsychosocial approaches in the physical therapy treatment of a patient with adverse neural tissue tension of the upper extremity.

\section{Case Description}

A thorough history of the patient was obtained during the initial examination. The patient was asked a series of questions related to the patient's occupation, demographics, and health status as outlined in the Guide to Physical Therapist Practice 3.0 (Guide) [26]. The patient denied any symptoms of recent unexplained weight loss, night sweats or chills, fever, or a general feeling of malaise that may infer a non-musculoskeletal contribution to presentation. A review of systems for the patient's cardiovascular, pulmonary, integumentary, and musculoskeletal systems was performed during the examination as described in the Guide [26] and was found to be normal.

The patient was a forty-year-old female who presented to physical therapy with a worker's compensation case the day after an injury to the right second digit metacarpophalangeal (MCP) joint. The patient was working in a warehouse as a stocker when the right second MCP joint was wedged between a box and a shelf while she was moving the box to the shelf. The patient denied any previous injury or functional limitations of the right second metacarpophalangeal joint or the surrounding areas prior to the injury. The patient's reported job requirements included the use of the both hands for grasping, gripping, lifting, carrying, pushing, and pulling objects of various shapes, sizes, and weights in a warehouse. The patient reported right hand dominance with daily tasks and workrelated tasks and was presently unable to use the right hand due to pain at the time of the examination. The patient provided informed consent prior to the start of the initial

The patient's chief complaint was 7/10 pain based upon the Numeric Pain Rating Scale (NPRS) in her right second MCP joint with pain radiating to the ipsilateral hand, wrist, and elbow. The patient stated the pain was elevated to a 9/10 with movement of the right second MCP joint. The NPRS is a pain rating scale of 0 representing no pain and 10/10 representing severe pain [27]. The patient stated that she tried to decrease the pain in the right MCP with no relief. The pain was described as a constant, sharp, throbbing pain. The patient also stated that she was experiencing numbness and tingling in the ipsilateral hand. The patient reported she was unable to grip or grasp due to pain and weakness in the right hand. Pain medication was prescribed to the patient, however, she had not taken any pain medication prior to the physical therapy initial examination because the prescription was not filled prior to the patient presenting to 
physical therapy.

The first objective component of the initial examination included a structural inspection. The patient presented with a downwardly rotated right scapula evident by the inferior angle of the scapula positioned more medially as compared to the spine of the scapula. The right scapula was positioned less than the average of three inches from the spine [17]. The position of the right scapula was consistent with scapular insufficient upward rotation syndrome as described by Sahrmann [17]. Scapular downward rotation syndrome may decrease the neural excursion of the peripheral nerves by the characteristic insufficient upward rotation of the scapula and shortened scapular downward rotator muscles, namely Rhomboid Major and Minor and Levator Scapulae [17]. The right humeral head was positioned anteriorly by evidence of one-third of the humeral head anterior and lateral to the acromion which is consistent with humeral anterior glide syndrome described by Sahrmann [17]. Additionally, the humeral head was medially rotated with and without the presence of correct alignment of the scapula which is consistent with humeral medial rotation syndrome described by Sahrmann [17]. The anterior and medial position of the humeral head may lead to compression on the cords of the brachial plexus subsequently resulting in adverse neural tissue tension on the peripheral nerves. Upon the physical therapist correcting the movement impairment syndromes, the patient stated there was a relief in symptoms which is consistent with the movement systems approach to further suspect movement dysfunction [17]. The decrease in neural symptoms with positional correction indicated that the scapular downward rotation, humeral anterior glide and humeral medial rotation syndromes were contributing to the neuropathic pain in the patient's right upper extremity.

Additional observations made during the structural inspection were forward head posture and an increased thoracic kyphosis. According to Sahrmann cervical extension rotation syndrome is typically seen in those patients with forward head posture and an increased thoracic kyphosis [18]. Cervical extension rotation syndrome can be increased by the altered alignment of the scapula in a downward direction [18]. To determine the presence of cervical extension rotation syndrome, the patient was asked to perform cervical ROM of flexion, extension, lateral flexion, and rotation. The patient reported pain with both cervical extension and right rotation with a bias into extension when rotating to the right. Moreover, rotation of the cervical vertebrae to the right was noted during right shoulder flexion further solidifying the presence of cervical extension rotation syndrome [18].

Tests and measures of joint integrity and function, muscle performance, pain, and range of motion (ROM) as described by the Guide were conducted [26]. A standard finger goniometer was used to measure the patient's ROM. The intra-rater reliability of goniometric measurement using a standard finger goniometer are 0.89 for MCP flexion and extension indicating a good reliability [28]. Upon measurement of the patient's right MCP, she was able to achieve five degrees of active range of motion (AROM) flexion and zero degrees of AROM ex- 
tension limited by pain. Accessory mobility assessment of the joint was deferred due to patient's level of pain. She presented with decreased right AROM of radiocarpal joint flexion and extension of forty degrees and thirty-five degrees, respectively. Further AROM assessment of the right wrist revealed extension radial deviation syndrome which is characterized by radial deviation of the radiocarpal joint during wrist extension [29]. Wrist extension radial deviation syndrome is often the result of an imbalance of strong extrinsic wrist extensors and weak intrinsic muscles of the hand including the lumbricals and interossei [29]. The patient may present with tight wrist extensors on the radial side of the forearm [28]. Furthermore, wrist extension with radial deviation syndrome can slacken the peripheral nerves and lead to neuropathic pain upon lengthening of the nerve during functional activities [28].

Following AROM assessment of accessory joint mobility was performed. Accessory mobility testing is an integral part of manual therapy [30] and is assessed passively by an external force that allows the physical therapist assess joint restrictions or increased movement of a joint [30] [31]. The passive movement of the joint promotes an environment conducive to the physical therapist acknowledging an end-feel, [31]. or a more simply a specific impression noted at the end of the joint's available range. A 2009 study by Staes et al. found the accessory mobility assessment of the carpal joints to have moderate to excellent intra-rater and inter-rater reliability. The intra-rater reliability was found to be greater than the inter-rater reliability [30]. Another study from 2010 by van de Pol et al. found that the joints that are larger with limited mobility resulted in poor inter-rater reliability, however smaller joints with more mobility such as the interphalangeal joints revealed excellent inter-rater reliability [31]. Furthermore, the intra-rater and inter-rater reliability of the end-feel of the accessory mobility was found to be very good [30]. Accessory mobility assessment of the MCP joint was deferred due to the patient's level of pain. Accessory mobility assessment of the right radiocarpal joint revealed decreased mobility and pain with an anterior glide. The accessory mobility assessment of the right second MCP joint revealed decreased mobility and pain with anterior and posterior glides as well as distraction all with an abnormal capsular end-feel.

Muscle length testing revealed tightness of the right Extensor Carpi RadialisLongus (ECRL) and the Extensor Carpi Radialis Brevis (ECRB) as described by Kendall [32] which supported the movement systems impairment of wrist extension radial deviation [29]. Manual muscle testing (MMT) of the finger flexors and extensors were deferred due to an increase in pain reported with muscle contraction.

Due to the patient's subject report of an inability to functionally grip or grasp, a grip strength test was administered with a standardized dynamometer. The dynamometer was set at the second handle position which has been shown to demonstrate maximal grip strength in most healthy adults [33]. The patient was able to grip thirty-five pounds with her left hand and was able to grip zero pounds with the right hand with the elbow flexed to ninety degrees. In 2015 
Harlinger et al. published a study demonstrating the normative data related to grip strength. The study revealed that an individual's dominant hand, which was self-identified by the individual, was stronger than the non-dominant hand [34]. The study also revealed the greatest grip strength was measured when the elbow was flexed [34].

Additional tests were performed due the mechanism of injury suggesting neural involvement of the peripheral nerves. ULTTs of the right Median, Ulnar, and Radial Nerves were positive indicating neural tension. A positive ULTT is the result of symptom reproduction during the test with most distal or most proximal joint movement either increasing or decreasing the patient's symptoms [11]. Using valid and reliable ULTTs is therefore utilized in the differential diagnosis to determine the cause of the patient's neuropathic pain [11]. The key to the ULTT is to elongate the peripheral nerve and determine if the result of the elongation reproduces the patient's symptoms. In order to achieve the full length of the peripheral nerve, standardized ULTTs have been developed and are widely known as ULTT1 for median nerve bias, ULTT2a also for median nerve bias, ULTT2b for radial nerve bias, and ULTT3 for ulnar nerve bias [10] [11]. Additional neural testing included special tests. The Tinel's special test is a test for adverse neural activity with the use of percussion over the peripheral nerve in a superficial area of the body [35]. Tinel's sign was positive for the right median nerve at the wrist and positive for the right ulnar nerve at the wrist and the cubital tunnel. There has been no standardization of Tinel's test and there is a large discrepancy of intra- and inter-rater reliability when performing the test [34]. Other special tests utilized were the Phalen's test and Reverse Phalen's test which were also found to be positive implicating right Median Nerve involvement. Phalen's test and Reverse Phalen's test are considered positive if symptoms are present in the first three digits after sixty seconds with the wrist is fully flexed and fully extended, respectively [36]. The patient also presented with hypersensitivity, which was described as painful, to light touch in the C5-T1 dermatome patterns of the right upper extremity.

\section{Patient Evaluation}

The World Health Organization established the International Classification of Functioning, Disability and Health (ICF) to create a common language among physical therapists to communicate about the impairments and limitations of patients [37] [38] [39]. The ICF includes domains of body structure and function at the physiological systems level, activity limitations at the individual level, and participation restriction at the societal level [36] [37] [38]. Physical therapy treatment and patient management can be centered on the ICF domains to improve the patient's physiological systems, individual activities, and societal roles [37] [38]. The ICF model proposes that the patient will have primary impairments due the dysfunction in any of the three domains as well as secondary impairments that are the result of the primary impairment and can further limit the patient or increase that patient's level of dysfunction [37]. 
The patient's primary impairments, according to the ICF, included loss of AROM and loss of accessory motion of the second MCP and the radiocarpal joint and decreased grip strength. Additionally, the patient had a primary impairment of the right Median, Radial, and Ulnar Nerves. The patient's secondary impairment included pain in the right second MCP and radiocarpal joint.

Activity limitations that included decreased ability to grip and grasp objects at work and home. Participation restrictions included inability to perform occupational tasks and work at her regular job. The patient's medical doctor placed her on modified work duty that restricted her from gripping, squeezing, or pinching with the right upper extremity. The medical doctor also predicted a period of maximal medical improvement to be two weeks from the date of injury.

From a manual therapy standpoint, the patient was given a physical therapy diagnosis of a right hypomobileradiocarpal joint with a posterior to anterior glide with an abnormal capsular end-feel and adverse neural tissue tension of the right median, radial, and ulnar nerves. From a movement systems standpoint, the patient was given a physical therapy diagnosis of cervical extension rotation syndrome, scapular downward rotation syndrome, humeral anterior glide syndrome, humeral medial rotation syndrome, and wrist extension with radial deviation syndrome which most likely lead to the adverse neural tissue tension of the right Median, Ulnar, and Radial Nerves.

\section{Plan of Care}

The plan of care was aimed to improve the patient's function by providing manual therapy, neuromuscular reeducation, therapeutic exercise, and therapeutic activities simulating her occupational tasks. Manual therapy was provided to the hypomobile joints to promote normal movement within the joints which has been shown to improve the mechanical motion of the joint thereby increasing motion [12] [13] [14] [15]. The movement systems approach as described by Sahrmann and associates [17] [18]. was used to determine the patient's resting posture and to determine the potentially weak muscles contributing to the abnormal resting posture and the adverse neural tissue tension of the right Median, Ulnar, and Radial Nerves. Biopsychosocial concepts of educating the patient of the anatomical structures that were contributing to dysfunction, answering questions the patient had about the physical therapy process, and explaining the patient's role in physical therapy [19] [20]. were included during the intervention to empower the patient with education related to her structure and functional impairments, activity limitations, and participation restrictions. These interventions were selected to address each impairment identified in the examination. The frequency and duration of treatments to meet the goals were set at three times per week for two weeks for a total of six physical therapy visits which was in accordance with the referring physician's order of six physical therapy visits. The patient was not scheduled for more than two visits consecutively per week to allow the patient time to complete her home exercise program (HEP) and incorporate new exercises and education strategies given into her functional tasks. 
Goals established for the patient were based on function and mobility. The first goal established was to achieve independence with the HEP created by the physical therapist. Other goals included a decrease in pain from the initial value of $7 / 10$ to $2 / 10$, an increase in AROM of the right radiocarpal flexion from forty degrees to eighty degrees, and an increase in AROM of the right radiocarpal extension from thirty-five degrees to seventy degrees. A functional occupational-related goal was set to increase the right hand grasping ability from zero pounds to thirty pounds in order to perform work and daily functions that require grasping ability. Return to work full duty was the ultimate goal. All goals were set to be achieved after the two week duration of physical therapy treatments. The patient was educated that she had six physical therapy visits lasting an hour per visit over a two week period.

The prognosis for the patient was good because the patient was young, apparently healthy, and highly motivated to increase her function and return to her regular work duties.

\section{Implementation of Intervention/Re-Assessment}

During the initial evaluation the patient was educated on her physical therapy diagnosis, the signs and symptoms associated with adverse neural tissue tension of the median, ulnar and radial nerves, as well as the plan of care and the rationale for using each intervention. Furthermore, patient education included a focus on deemphasizing the pain once the source of pain was explained while emphasizing the gained function at each physical therapy visit. Fear and anxiety can often be at the forefront of the patient's concerns when entering a rehabilitation program so allowing the patient to recognize the challenges that may ensue with the rehabilitation process promotes the patient to construct a preparation phase [20]. The patient's preparation for rehabilitation, which includes being an active participant in both the physical therapy clinic and out of the clinic with an HEP, allows the patient to demonstrate her commitment to her own health [20]. By supporting the patient's preparation and commitment to her health, the physical therapy can assist in building the patient's confidence and trust in herself and in the rehabilitation process [19]. Throughout physical therapy the patient was encouraged to be an active participant in her rehabilitation by completing the exercises at home and taking responsibility for her functional improvement.

Since pain has the potential to limit function, the numeric pain rating scale (NPRS) was used as tool for the patient's report of pain. NPRS is a means of measuring patient reported pain on a scale of zero representing no pain and ten representing the worst pain experienced [28]. The minimal clinically important difference (MCID) of the NPRS has been determined to be two points demonstrating that a two point increase or decrease in the patient's reported pain level is clinically significant [40]. At the start of each physical therapy visit the patient was asked to report her pain level at rest and pain level with activity.

Treatment during the initial evaluation began with patient education as described above and then included manual therapy. Manual therapy was focused 
on improving joint mobility and decreasing neural tension. A thoracic spine facet joint posterior to anterior (P/A) mobilization for extension of the fifth on sixth vertebrae (T5/6) with high velocity, low amplitude mobilization was administered to the patient and resulted in decreased adverse neural tissue tension of the upper extremity peripheral nerves and the patient's subject report of pain (Figure 1). The manual therapy techniques administered were based on the joint mobilization grades described by Maitland. Refer to Table 1 for joint mobilization definitions and indications [41]. Additional manual therapy techniques administered are listed in Table 2.

Various neural mobilizations, which can be performed actively or passively, can promote neural excursion of the peripheral nerve [3]. The slider technique is used to administer a gliding motion of the peripheral nerve produced by combining alternating movements of two or more joints [42]. One movement results in an increase in tension on the nerve by lengthening and the other movement unloads the nerve to reduce the tension that was created [41]. Sliders are thought to provide an increase in neural excursion without a sustained tension on the

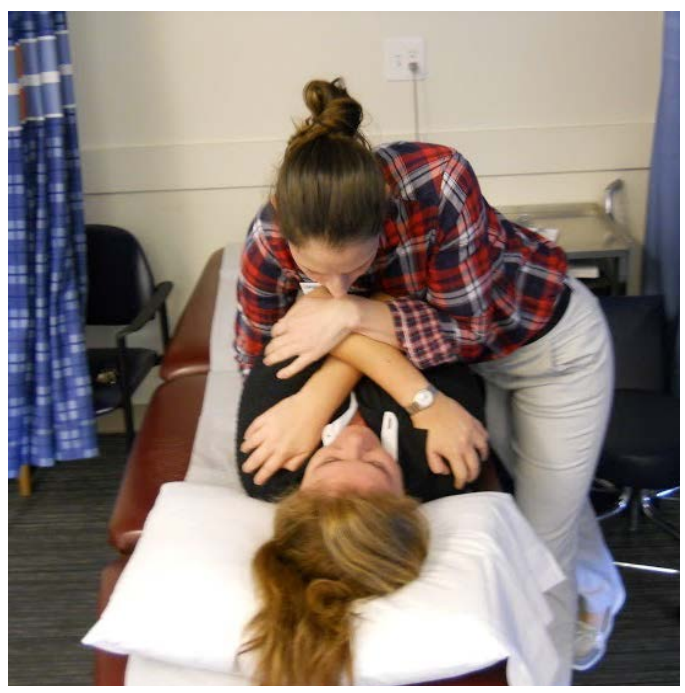

Figure 1. T5/6 Facet Joint mobilization, HVLA mobilization.

Table 1. Maitland joint mobilization grading definition and indications [41].

\begin{tabular}{|c|c|c|}
\hline Grade & Definition & Indication \\
\hline I & Low velocity, Low amplitude & Pain inhibition \\
\hline II & $\begin{array}{l}\text { Low velocity, Large amplitude in beginning to } \\
\text { middle of pathological range }\end{array}$ & Pain inhibition \\
\hline III & $\begin{array}{l}\text { Low velocity, Large amplitude in middle to end of } \\
\text { pathological range }\end{array}$ & $\begin{array}{l}\text { Mechanical change, } \\
\text { Pain inhibition }\end{array}$ \\
\hline IV & $\begin{array}{l}\text { Low velocity, Low amplitude at the end of } \\
\text { the pathological range }\end{array}$ & $\begin{array}{c}\text { Mechanical change, } \\
\text { Pain inhibition }\end{array}$ \\
\hline $\mathrm{V}$ & High velocity, Low amplitude (thrust) & $\begin{array}{c}\text { Mechanical change, } \\
\text { Pain inhibition }\end{array}$ \\
\hline
\end{tabular}


Table 2. Manual therapy and movement systems approach administered by physical therapy visit.

\begin{tabular}{|c|c|c|}
\hline Visit & Manual Therapy Techniques & Movement Systems Approach \\
\hline 1 & $\begin{array}{l}\text { - } \text { T5/6 facet joint gapping, HVLA mobilization } \\
\text { - } \text { C5/6 gaping, HVLA mobilization } \\
\text { - } \text { C2/3 gapping, Grade IV (Figure 2) } \\
\text { - } \text { Posterior glide of occiput on atlas, progressive oscillations } \\
\text { - } \text { CTJ distraction HVLA mobilization } \\
\text { - Inferior glide of the first costovertebral joint, progressive } \\
\text { - } \text { oscillations and breathing } \\
\text { - } \quad \text { Anterior glide of AC joint with shoulder flexion, HVLA } \\
\text { - } \text { mobilization } \\
\text { - } \quad \text { Radiohumeral joint gapping, HVLA mobilization }\end{array}$ & \\
\hline 2 & $\begin{array}{ll}\text { - } & \text { T5/6 facet joint gapping, HVLA mobilization } \\
\text { - } & \text { CTJ distraction, HVLA mobilization } \\
\text { - } & \text { First costovertebral joint mobilization with breathing } \\
\text { - } & \text { GHJ posterior and inferior glides, Grade III and IV } \\
\text { - } & \text { Radiohumeral joint gapping, HVLA mobilization } \\
\text { - } & \text { Radiocarpal distraction, HVLA mobilization }\end{array}$ & $\begin{array}{l}\text { - DNF with static craniocervical flexion exercise } \\
10 \text { seconds } 10 \text { times at } 22,24,26 \text {, and } 28 \mathrm{mmHg} \\
\text { - DNF staticcraniocervical flexion exercise with } \\
\text { concurrent shoulder flexion } \\
\text { - Middle Trapezius "T" exercise } \\
\text { - Lower Trapezius "Y" exercise } \\
\text { - Serratus Anterior exercise in quadruped }\end{array}$ \\
\hline 3 & $\begin{array}{l}\text { - T5/6 facet joint gapping, HVLA mobilization } \\
\text { - Radiohumeral joint posterior to anterior mobilization, HVLA } \\
\text { - } \text { mobilization } \\
\text { Radiocarpal volar glides, HVLA mobilization }\end{array}$ & $\begin{array}{l}\text { - DNF with static craniocervical flexion exercise } 10 \\
\text { - } 10 \text { DNF static craniocervical flexion exercise with } 10 \text { times at } 22,24,26 \text {, and } 28 \mathrm{mmHg} \\
\text { concurrent shoulder flexion } \\
\text { - "Number 3" wrist extension exercise } \\
\text { - Lumbrical exercise with putty }\end{array}$ \\
\hline 4 & $\begin{array}{l}\text { - T5/6 facet joint gapping, HVLA mobilization } \\
\text { - Radiocarpal volar glides, Grade IV, } \\
\text { - Second MCP distraction, Grade III }\end{array}$ & $\begin{array}{l}\text { - DNF with static craniocervical flexion exercise } 10 \\
\text { - } \quad \text { Middle Trapezius "T" exercise } \\
\text { - Lower Trapezius "Y" exercise } \\
\text { - "Number 3" wrist extension exercise }\end{array}$ \\
\hline 5 & $\begin{array}{l}\text { - T5/6 facet joint gapping, HVLA mobilization } \\
\text { - }\end{array}$ & $\begin{array}{l}\text { - DNF with static craniocervical flexion exercise } 10 \\
\text { seconds } 10 \text { times at } 22,24,26 \text {, and } 28 \mathrm{mmHg} \\
\text { - DNF static craniocervical flexion exercise with } \\
\text { concurrent shoulder flexion } \\
\text { - Middle Trapezius "T" exercise } \\
\text { - Lower Trapezius "Y" exercise }\end{array}$ \\
\hline 6 & - T5/6 facet joint gapping, HVLA mobilization & $\begin{array}{l}\text { - DNF with static craniocervical flexion exercise } 10 \\
\text { seconds } 10 \text { times at } 22,24,26 \text {, and } 28 \mathrm{mmHg} \\
\text { - DNF static craniocervical flexion exercise with } \\
\text { concurrent shoulder flexion } \\
\text { - Middle Trapezius "T" exercise } \\
\text { - Lower Trapezius "Y" exercise }\end{array}$ \\
\hline
\end{tabular}

$\mathrm{CTJ}=$ Cervicothoracic junction, $\mathrm{GHJ}=$ glenohumeral joint, $\mathrm{AC}=$ acromioclavicular, $\mathrm{MCP}=$ metacarpophalangeal, $\mathrm{DNF}=$ deep neck flexor, $\mathrm{mmHg}=\mathrm{mil}-$ limeters of mercury.

nerve and promotes movement without significant strain [3] [42]. A progression from the slider is the "tensioner" which is more aggressive on the peripheral nerve [3]. The tensioner is designed to produce a tensile load on the peripheral nerve to oscillate the nerve to decrease the protective muscle guarding that is 


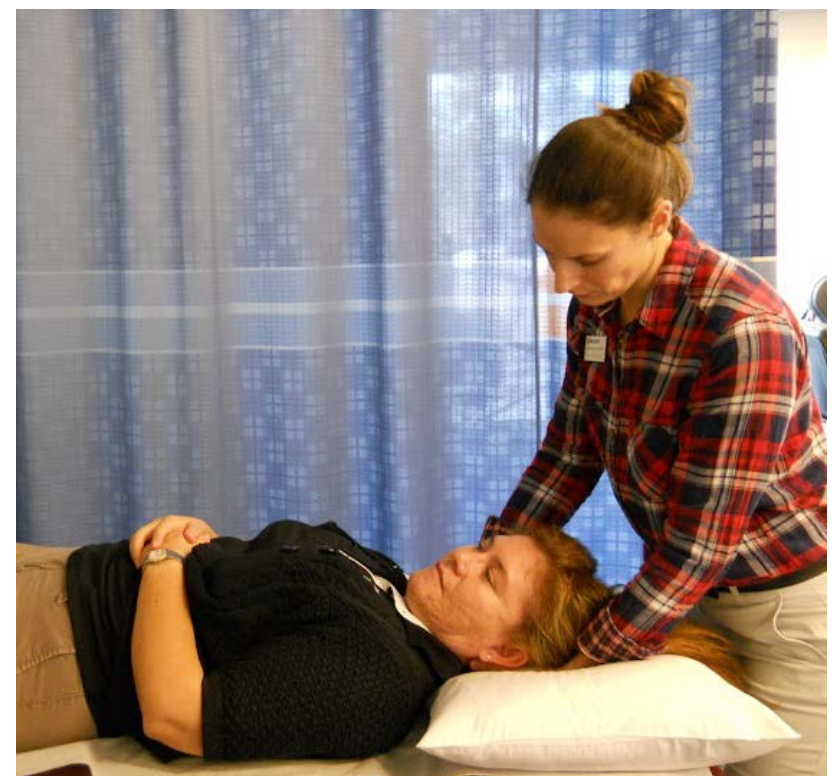

Figure 2. C2/3 upglide, Grade IV.

typically present with adverse neural tissue tension as well as elongate the nerve [3] [42]. The elongation of the nerve is not to be confused with "stretching" the nerve; the tensioner technique's focus is elongating the nerve from a stationary nerve bed in order to promote nerve health, restore length, and tolerate lengthening and strain to protect the nerve from further insult [3]. Since sliders have shown to be less aggressive, they may be a better treatment option for acute nerve injuries [42]. Therefore, the patient was educated with Median Nerve sliders to decrease the neural tension in the Median, Ulnar, and Radial Nerves, as the Median Nerve slider provided the greatest amount of neural excursion [43]. Employing sliding techniques either passively or actively can increase the nerve excursion across and between tissues along the nerve's path [3]. A program that includes neural mobilization techniques has been shown to reduce a patient's perception of pain and increase function due the nerve's improved efficiency in tissue innervation [3].

The patient was shown stretches for the ECRL and ECRB because of tightness revealed during the muscle length test. To address the decreased grip strength and grasping ability, the patient was instructed to grasp soft putty and in use of a Digiflex grip strengthener. The patient's HEP after the first visit included median nerve sliders, ECRL and ECRB stretches, and the grasping of the putty and the Digiflex. The patient was given a Digiflex and putty to take home for use with her HEP.

Patient returned for the second visit with report of $4 / 10$ pain at rest on the NPRS and 6/10 with activity, which was an improvement from the 7/10 subjective pain report at rest and $9 / 10$ pain with activity at the time of evaluation. Upon further reassessment, the patient demonstrated an increase in AROM of right wrist flexion to seventy degrees and an increase in extension of seventy degrees. The patient also had an increase in right grip strength of fifteen pounds. 
The patient demonstrated the continued presence of neural tension in the peripheral nerves by evidence of positive ULTTs for the right median, ulnar, and radial nerves. Additional testing was performed on the second visit that was deferred on the first visit either due to pain or inability to attain the test position. MMT revealed a weak right Middle Trapezius (4/5), a weak right Lower Trapezius (3+/5), and a weak right Serratus Anterior (3+/5). Refer to Table 3 for the MMT grading and definitions according to Kendall [31]. Bilaterally the patient demonstrated weakness and decreased endurance of the deep neck flexor muscles (DNF) according to the classification described by Jull et al. with testing the craniocervical flexion test [44]. The patient was able to correctly demonstrate the exercises of her HEP.

The treatment of the second visit continued with manual therapy. The manual therapy administeredis detailed in Table 2. Neuromuscular reeducation followed the manual therapy and included reeducation of the DNF with static craniocervical flexion exercise held for ten seconds ten times at 22, 24, 26, and 28 $\mathrm{mmHg}$ on a sphygmomanometer placed under the subcranial spine as described by Jull et al. (Figure 3) [44]. The progression of strengthening the DNF muscular can benefit the patient by increasing the patient's control over neck motion and the ability to sustain correct posture [44]. To promote correction of the identified cervical extension rotation syndrome at the cervical spine, DNF static chin tucks were held with concurrent shoulder flexion (Figure 4). Falla et al. described the use of DNF static craniocervical flexion exercise and concurrent

Table 3. MMT grades and definitions according to Kendall [32].

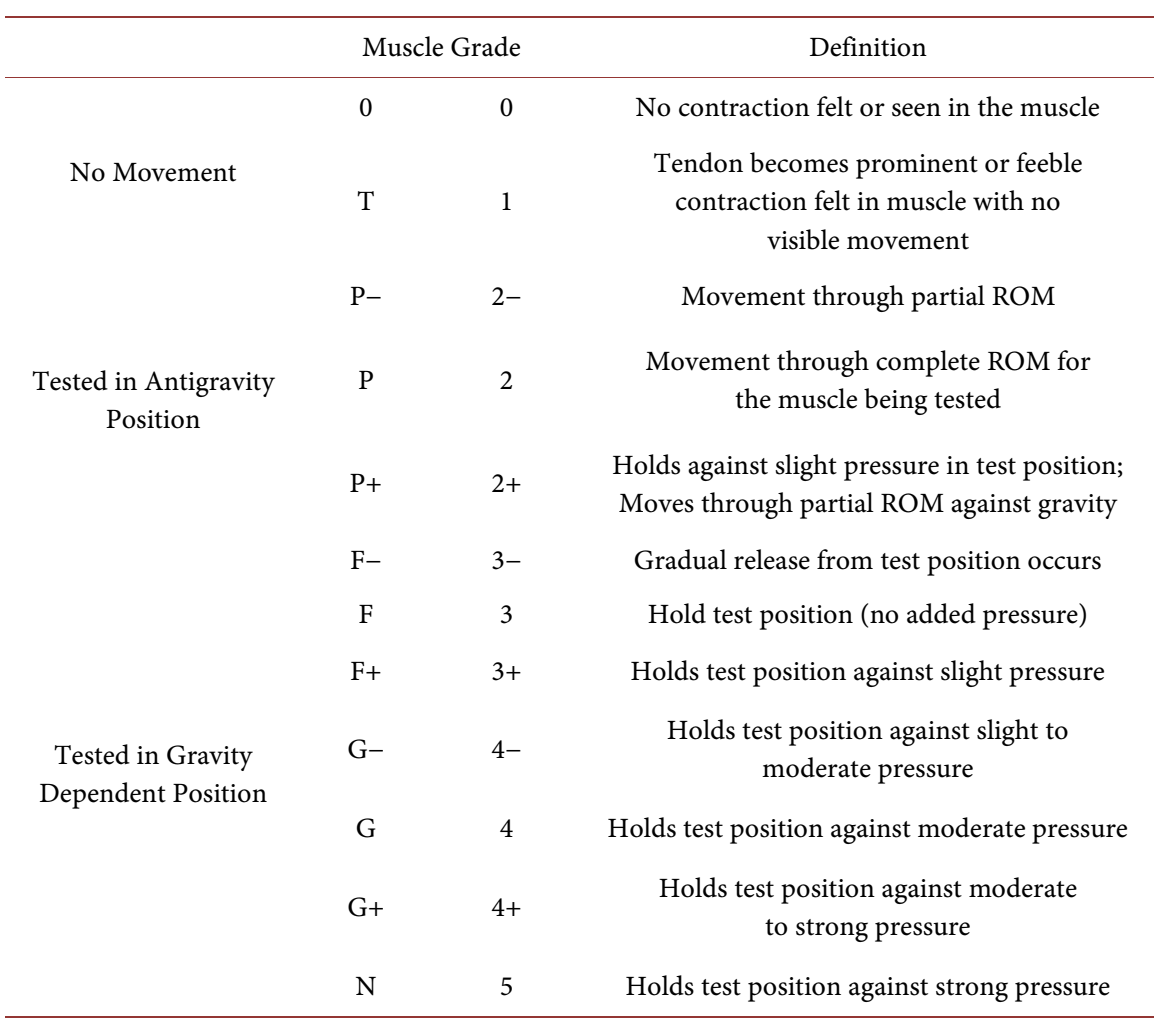

$\mathrm{T}=$ Trace, $\mathrm{F}=$ Fair, $\mathrm{G}=$ Good, $\mathrm{N}=$ Normal. 


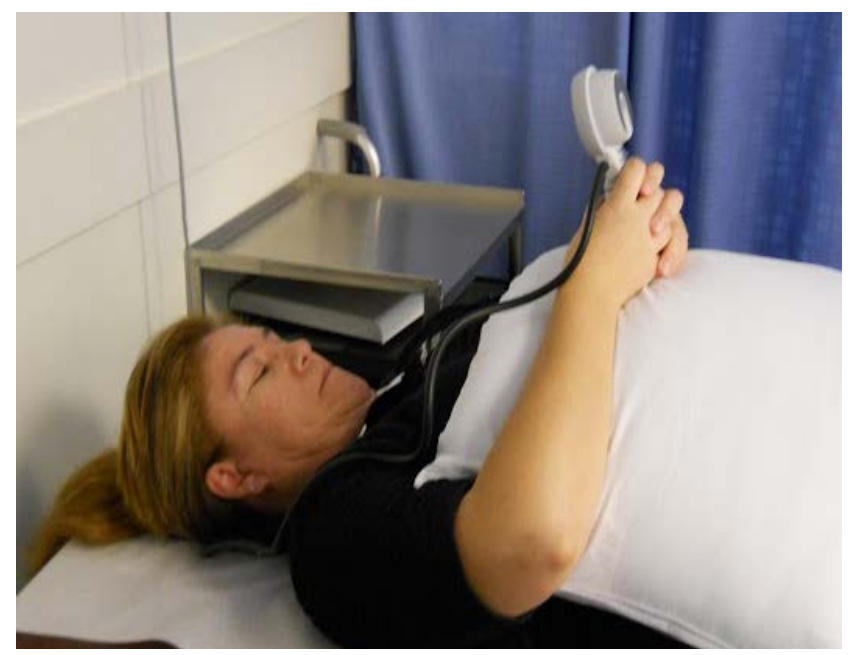

Figure 3. DNF neuromuscular reeducation static craniocervical flexion exercise with sphygmomanometer under subcranial spine.

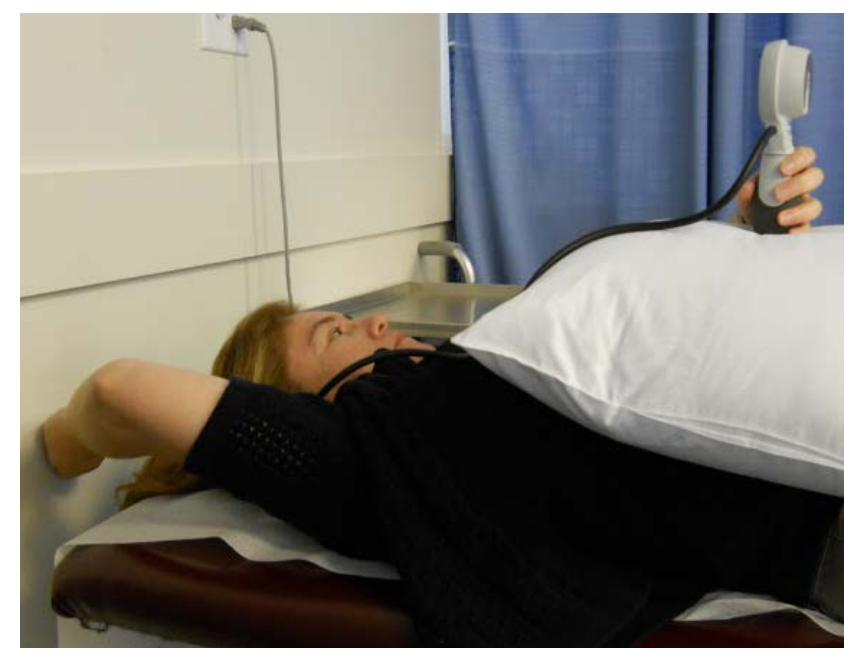

Figure 4. DNF static craniocervical flexion exercise with concurrent shoulder flexion.

shoulder flexion as a means to provide stability of the cervical spine before peripheral limb movement [45]. Stability of the cervical spine before movement may improve dynamic postural positions [45]. Additional neuromuscular reeducation was also directed toward increasing motor control and strength by use of a "T" exercise in prone for Middle Trapezius reeducation (Figure 5), a "Y" exercise for Lower Trapezius (Figure 6), and Serratus Anterior modified push-up plus exercise in quadruped. Electromyographic research has demonstrated that the prone abduction exercise with humeral external rotation, the prone flexion exercise with a slight bias into abduction, and the push-up plus exercise are the best exercises for strengthening the Middle Trapezius, Lower Trapezius, and Serratus Anterior muscles, respectively [46]. The patient was also given ECRL and ECRB stretch (Figure 7). The exercises added to the patient's HEP are in Table 4. 
Table 4. HEP by physical therapy visit.

\begin{tabular}{ll}
\hline Visit \\
\hline 1 \\
\hline
\end{tabular}

HEP $=$ Home Exercise Program, ECRL $=$ Extensor Carpi RadialisLongus, ECRB = Extensor Carpi RadialisBrevis, DNF = Deep Neck Flexor.

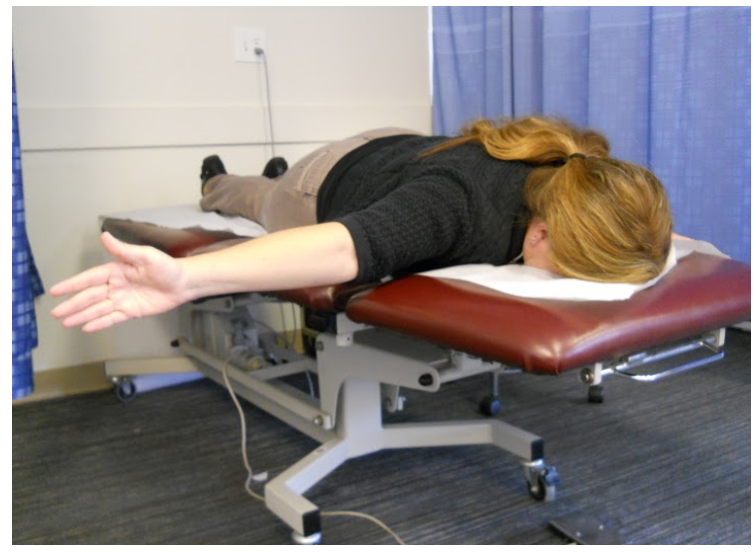

Figure 5. "T" exercise in prone for Middle Trapezius reeducation. 


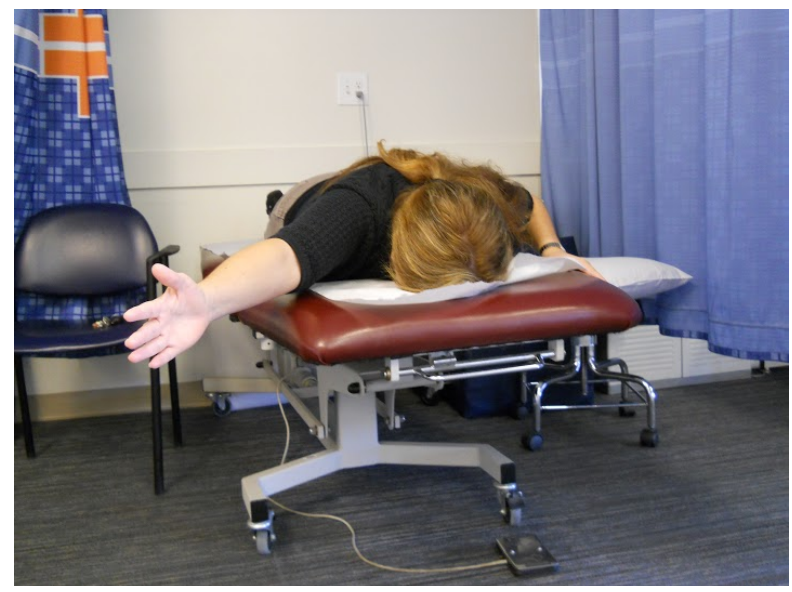

Figure 6. "Y" exercise in prone for Lower Trapezius reeducation.

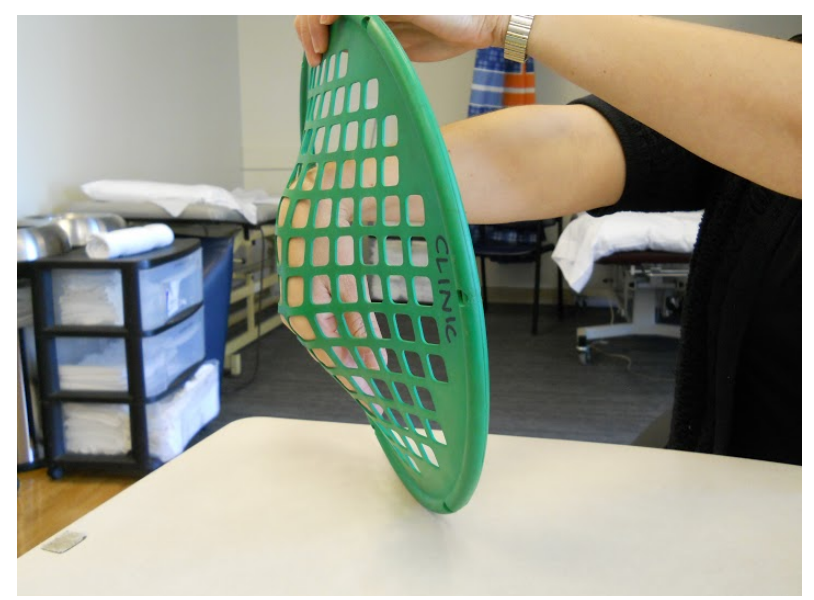

Figure 7. ECRL and ECRB stretch.

The treatment for the third visit again started with reassessment of the patient's reported pain level and ULTTs. The patient reported 3/10 with rest and 4/10 pain with activity. The patient demonstrated a decrease in adverse neural tissue tension by an increase in movement during the ULTTs for the median, ulnar, and radial nerves. The accessory mobility of the right second MCP was assessed and was determined to be hypomobile in all directions. Manual therapy, listed in Table 2 followed the reassessment. The neuromuscular reeducation administered included static DNF exercises and DNF static craniocervical flexion exercise with concurrent shoulder flexion exercises. The patient completed median nerve sliders, "Number 3" wrist extension exercises (Figure 8 and Figure 9) and lumbrical exercises with putty to correct the movement dysfunction of wrist extension with radial deviation. Considering wrist extension radial deviation syndrome presents with a weakness of the intrinsic muscles of the hand, restoring strength of the lumbricals will aid in the restoration of wrist extension without the radial deviation pattern [28]. The patient performed ECRL and ECRB stretches.

The fourth treatment started with reassessment of the patient's reported pain 


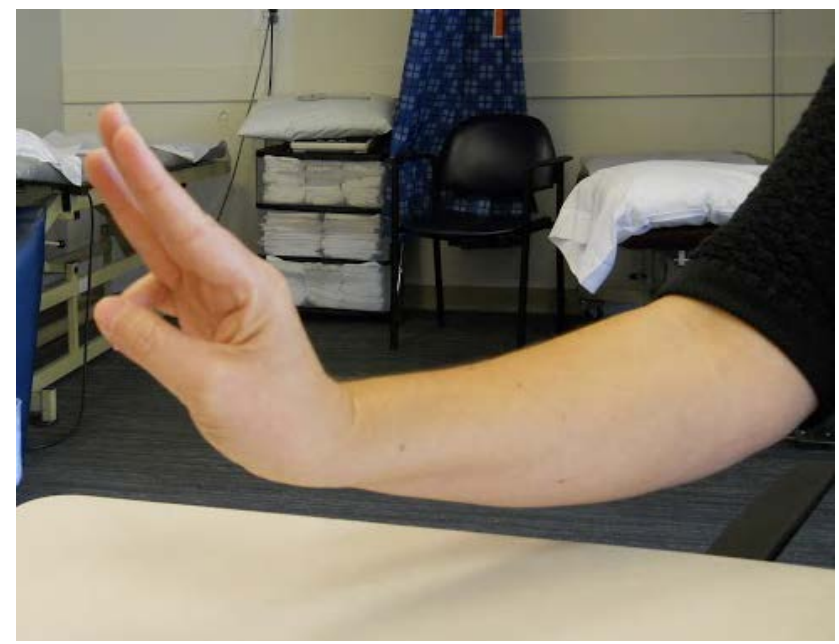

Figure 8. Starting position of "Number 3" neuromuscular reeducation exercise [28].

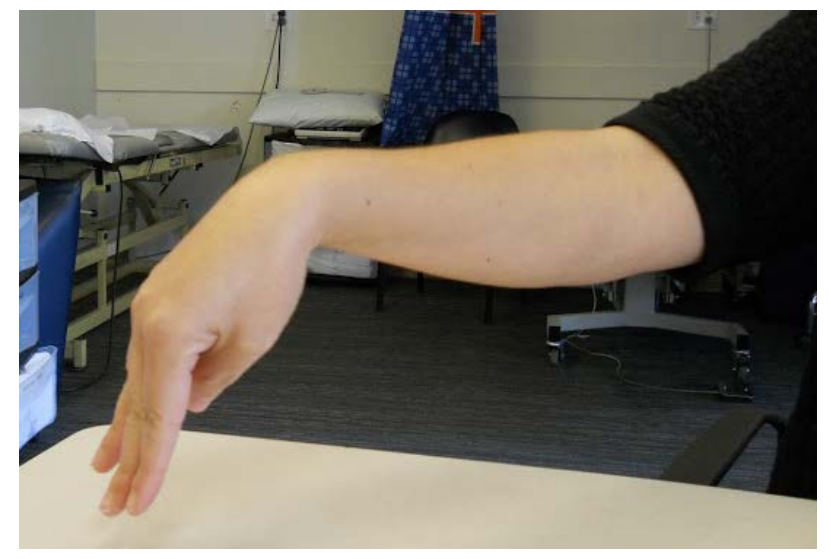

Figure 9. Ending position of "Number 3" neuromuscular reeducation exercise [27].

on the NPRS which was $0 / 10$ with rest and 2/10 with activity. Assessment of the ULTT of the median, ulnar, and radial nerves revealed no presence of adverse neural tissue tension. ULTTs on the right did not elicit any symptoms and were equal to the ULTTs on the left. Manual therapy interventions were continues as described in Table 2. Strengthening exercises administered included DNF static exercises, DNF static chin tuck with concurrent shoulder flexion, Middle Trapezius "T" exercises, Lower Trapezius "Y" exercises, and "Number 3" wrist extension exercises. During the fourth visit therapeutic activities related to the patient's occupation were introduced to the physical therapy session. The patient completed fifteen minutes of reaching, grasping, and lifting objects of different sizes, shapes, and weights with emphasis on proper body mechanics to reduce the identified movement dysfunctions.

The reassessment during the fifth treatment revealed the patient's reported pain of $0 / 10$ on the NPRS for both rest and activity. The ULTTs of the right extremity remained negative and within normal limits as compared to the contralateral limb. Manual therapy and strengthening exercises continued as outlined 
in Table 2. Therapeutic activities simulating the patient's occupation were increased from fifteen minutes to thirty minutes. The patient completed tasks of reaching, grasping, and lifting objects of different sizes, shapes, and weight with emphasis on proper body mechanics for fifteen minutes. The patient also completed fifteen minutes of grasping putty and reaching with it to simulate occupational tasks.

During the sixth and final visit the patient was reassessed. The patient reported 0/10 pain on the NPRS for both rest and activity (Table 5), measured AROM of right wrist flexion and extension were eighty-five degrees and seventy degrees, respectively, and grip strength of thirty-two pounds with the dynamometer. The outcomes of goniometric measurements, grip strength, FABQ-W, FABQ-PA, and QuickDASH are displayed in Table 3. At the end of the six treatment visits the patient met or exceeded all of the physical therapy goals. There was no presence of adverse neural tissue tension due to the right ULTTs not eliciting symptoms and negative results for the Tinel's, Phalen's and Reverse Phalen's tests. The patient was able to perform regular and occupational tasks without pain or compensation therefore there was no need to continue physical therapy services after the sixth visit. The manual therapy administered was T5/6 facet joint gapping with HVLA mobilization (Table 2). The strength exercises and therapeutic activities for the sixth visit were the same as the fifth visit.

As the treatments progressed the patient required less manual treatment as the joints reached normal mobility with normal end-feels. An increase in emphasis was then placed on strengthening as the treatments progressed to support the position of the joints after the manual therapy was administered. Refer to Table 2 for a detailed description of the manual therapy and neuromuscular reeducation interventions or progressions. As the patient progressed with a decrease in pain based on the NPRS and an increase in function, the treatments included an increase in therapeutic activities simulating occupational duties to prepare the patient for a return to her full duty. The progression of the treatments was assisted by the patient completing her HEP that included the strengthening exercises and the stretches for the ECRL and ECRB that were taught during the treatment sessions. She was instructed to continue with her HEP to maintain the gains achieved during the physical therapy treatment (Table 4). The HEP exercises were chosen to provide the patient with correct movement

Table 5. NPRS scores by physical therapy visit.

\begin{tabular}{ccc}
\hline Visit & NPRS Score at Rest & NPRS Score with Activity \\
\hline 1 & 7 & 9 \\
2 & 4 & 6 \\
3 & 3 & 2 \\
4 & 0 & 0 \\
5 & 0 & 0 \\
6 & 0 & 0 \\
\hline
\end{tabular}

NPRS $=$ Numeric Pain Rating Scale. 
and to prevent movement dysfunctions of cervical extension and rotation, humeral anterior glide and medial rotation, and wrist extension and radial deviation which were identified during the initial evaluation using the movement systems approach.

\section{Outcomes}

At the end the six treatment visits the patient met or exceeded all of the physical therapy goals. Pain was reported to decrease from $7-9 / 10$ or $0 / 10$ on the NRPS. From the initial evaluation to discharge at the sixth visit, the patient had changes in standardized outcome measures as follows: FABQ-W 17/42 to 10/42, FABQPA $15 / 24$ to $3 / 24$, QuickDASH $22.72 \%$ disability to $9.1 \%$ disability due to symptoms and $75 \%$ to $0 \%$ for work disability due to symptoms which are displayed in Table 6. Since the QuickDASH is a shortened version of the DASH the validity and reliability become an important component of the outcome measure to conclude if the shortened version is as applicable as the longer version. In 2014 Franchignoni et al. determined the validity of the QuickDASH to be $r=0.96$ and $r=0.97$ at follow up which indicate a good correlation when using a Pearson $r$ correlation to compare to the DASH [25]. The test-retest reliability of the QuickDASH was determined to be an ICC of 0.91 which indicates good testretest reliability [25]. The QuickDASH uses the same five item questionnaire as the DASH for both work and recreational activities such as sport or playing a musical instrument in addition to the questions related to disability of everyday activities [25]. The scores of the DASH and QuickDASH are calculated into percentages to determine the percentage of disability of each section. In 2010 Polson et al. determined that the minimal importance difference (MID) of the QuickDASH is nineteen points from baseline to reassessment. Additionally, the minimal detectable change (MDC) of the QuickDASH was determined to be eleven points [24].

In addition to demonstrating an improvement with abilities and FABs, the patient demonstrated an increase in AROM in both wrist flexion and extension of the right wrist as well as in increase in grip strength of the right hand which provided her the ability to fully function with regular work duties which included grasping, reaching, and lifting objects of various size, shape, and weight. Since the patient met all of the physical therapy goals established related to impairments and function and was able to perform all occupational related duties safely,

Table 6. Outcome measurements from evaluation and discharge.

\begin{tabular}{|c|c|c|c|c|}
\hline Visit & Goniometric Measurements & Grip Strength & FABQ & QuickDASH \\
\hline Evaluation & $\begin{array}{l}\text { - Right wrist flexion: } 40^{\circ} \\
\text { - } \quad \text { Right wrist extension: } 35^{\circ}\end{array}$ & $\begin{array}{l}\text { - } \quad \text { Right: } 0 \text { pounds } \\
\text { - } \quad \text { Left: } 30 \text { pounds }\end{array}$ & $\begin{array}{ll}\text { - } & \text { FABQ-W: } 17 / 42 \\
\text { - } & \text { FABQ-PA: } 15 / 24\end{array}$ & $\begin{array}{l}\text { - } 22.72 \% \text { (disability) } \\
\text { - } \quad 75 \% \text { (work) }\end{array}$ \\
\hline Discharge & $\begin{array}{l}\text { - Right wrist flexion: } 85^{\circ} \\
\text { - Right wrist extension: } 70^{\circ}\end{array}$ & $\begin{array}{l}\text { - Right: } 35 \text { pounds } \\
\text { - Left: } 30 \text { pounds }\end{array}$ & $\begin{array}{ll}\text { - } & \text { FABQ-W: } 10 / 42 \\
\text { - } & \text { FABQ-PA: } 3 / 24\end{array}$ & $\begin{array}{l}\text { - } \quad 9.1 \% \text { (disability) } \\
\text { - } \quad 0 \% \text { (work) }\end{array}$ \\
\hline
\end{tabular}

FABQ-W = Fear Avoidance Belief Questionnaire-Work, FABQ-PA = Fear Avoidance Belief Questionnaire-Physical Activity, QuickDASH = Quick Disability of Arm, Shoulder, and Hand. 
without compensation, and with pain, she was discharged from physical therapy at the end of the sixth visit. The patient was instructed to continue the HEP given at the sixth visit for two weeks following physical therapy discharge.

Based on the ICF model, the patient's identified activity limitations were resolved in that she was able to grip and grasp objects independently at home and at work. The patient's identified participation restriction was also corrected because she was able to perform regular and full occupational duties.

\section{Discussion}

The purpose of this case report was to demonstrate the use of manual therapy, movement systems, and biopsychosocial approaches in the treatment of acute adverse neural tissue tension of the upper extremity. The combination of intervention tactics was found to be effective in the rehabilitation process of the patient. The patient demonstrated decreased FABs with each physical therapy visit as the patient met all physical therapy goals set during the initial evaluation and stated she was able to return to personal and occupational tasks that required use of her right upper extremity. The patient subjectively reported that she felt as though she had gained more function than she had before her injury, which can possibly be attributed to the patient's involvement in the physical therapy treatment.

Involving the patient and the patient's support system has been shown to be helpful in the patient's involvement in the rehabilitation process [7]. Using the biopsychosocial model of patient management to decrease the patient's FABs can be a valuable tool [7]. A patient should be encouraged to participate in the rehabilitation process as Elven et al. found this to result in a behavior change focused toward healing and positive physical therapy outcomes [45]. It has also been shown that a focus on pain, rather than on progress, can result in increased time to return to prior level of function [7]. Additionally, Elven et al. reported that a patient with a greater perception of self-worth is more likely to recover from an injury [47]. Conversely, fear and anxiety related to pain from the injury, work, or other external influences can contribute to the deleterious factors preventing healing and returning to prior level of function [7] [46]. Fear as the result of pain has been shown to decrease function and increase avoidance of activities that may provoke pain [7] [48]. Accurately determining a patient's FABs can be critical in knowing how to appropriately provide external motivation [47] [48].

The FABQ has been shown to be valid and reliable in patients with LBP [49]. However, in patients with upper extremity injuries the FABQ was found to be less reliable and valid [22]. Spearman $r$ correlations for the FABQ-PA was 0.61 and 0.54 for the $\mathrm{FABQ}-\mathrm{W}$ indicating good and moderate correlations, respectively, when compared to Shoulder Pain and Disability Index (SPADI) outcome measure [22]. The intraclass correlation coefficient (ICC) for the FABQ-PA was 0.52 and 0.59 for the FABQ-W indicating moderate correlations [22].

In the case of patient described, FABs were present due to the injury occurring 
the patient's place of employment. A multimodal approach was taken to provide support to the patient to decrease FABs. A multimodal approach may increase the patient's confidence and decrease FABs. However, a limitation of this case report is the use of a multimodal approach of which lacks a clear understanding of which intervention was helpful or if a combination of multiple interventions is most appropriate given the patient's presentation [49] [50]. Giving the multiple approaches from physical therapy and the pain medication prescribed to the patient by the physician may lead to an alternative explanation of the patient's outcome due to the use the pain medication. The patient's adverse neural tension symptoms may have subsided due to medication and an initial decrease in activity to promote decreased use of inflamed nerves.

Based on the mechanism of injury it can be surmised that the patient had AIGS present before the trauma to the right second MCP. The disruption of the neural impulses may contribute to the hypersensitivity of the peripheral nerves [3]. The trauma resulted in an increase of hypersensitivity of the peripheral nerves leading to adverse neural tissue tension. The patient's pain pressure threshold (PPT) was decreased over zygapophyseal joints in the cervical spine, the right radiohumeral joint, and the right radiocarpal joint. PPT has been shown to be decreased over areas of aberrant mechanical movement of the zygopaphyseal in patients with chronic neck pain [14]. Manipulation at the thoracic spine at the T3-T6 levels has shown to increase the PPT of patients with chronic neck pain and assist with decreasing FABs associated with pain [14].

Assessing movement system impairments and correcting movement dysfunction are becoming more of a focus for physical therapists [51]. According to Dr. Shirley Sahrmann, physical therapists should be regarded at the movement systems specialists [51]. With that responsibility, it comes to identifying movement dysfunction as a means of treatment or to prevent further exacerbation of a current condition [50]. Throughout a person's life movement patterns change due to disease, injury, or occupation. Addressing the movement dysfunction may increase the person's level of function [51]. The classification of a movement dysfunction arose from common patterns that emerged from muscle weakness, muscle tightness or joint position that are divided into categories predicting movement [51] [52]. The movement systems approach is not just applicable to patients with musculoskeletal disorders. Neurological disorders present with predictable movement patterns that can be useful in designing the patient's plan of care [52]. Using the movement systems approach allows physical therapists to truly become the movement specialist and provide interventions that restore or prevent dysfunction [52].

Future research focused on various combinations of manual therapy, movement systems, and biopsychosocial aspects of treatment is warranted to determine if various combinations improved outcomes to restore function and improve disability. Future research should also focus on a valid and reliable outcome measure depicting the FABs associated with upper extremity injuries. Moving forward, the use of manual therapy, movement systems, and biopsy- 
chosocial approaches may benefit physical therapists in restoration and prevention of dysfunction in patients.

\section{Acknowledgements}

CAS would like to acknowledge Physical Therapists past, present, and future for their contributions to such a rewarding profession. CAS would also like to acknowledge the help and support from Concentra Physical Therapy, The Manual Therapy Institute, and the University of St. Augustine for Health Sciences. LEP would like to acknowledge the contributions of Pieter Kroon, PT, DPT, OCS, FAAOMPT, Brenda Boucher, PT, PhD, CHT, OCS, FAAOMPT, and Tim Kruchowsky PT, DPT, OCS, FAAOMPT of The Manual Therapy Institute and Texas State University, who identified the examination and treatment for Wrist Extension-Radial Deviation movement systems impairment syndrome, and who presented on it at the American Academy of Orthopaedic Manual Physical Therapists Conference in 2014. LEP would also like to acknowledge Tim Kruchowsky PT, DPT, OCS, FAAOMPT, Pieter Kroon, PT, DPT, OCS, FAAOMPT, Andrew Okamoto, PT, DPT, IPNFA, FAAOMPT, and Annette Karim, PT, DPT, PhD, OCS, FAAOMPT of The Manual Therapy Institute for their excellent teaching and mentoring, through which he learned to integrate the manual therapy approach with a movement systems approach, with a focus on patient interaction and biopsychosocial education.

\section{References}

[1] Driver, D.F. (2006) Occupational and Physical Therapy for Work-Related Upper Extremity Disorders: How We Can Influence Outcomes. Clinics in Occupational and Environmental Medicine, 5, 471-482.

[2] Taylor, C.A., Braza, D., Rice, J.B. and Dillingham, T. (2008) The Incidence of Peripheral Nerve Injury in Extremity Trauma. American Journal of Physical Medicine \& Rehabilitation, 87, 381-385. https://doi.org/10.1097/PHM.0b013e31815e6370

[3] Nee, R.J. and Butler, D. (2006) Management of Peripheral Neuropathic Pain: Integrating Neurobiology, Neurodynamics, and Clinical Evidence. Physical Therapy in Sport, 7, 36-49. https://doi.org/10.1016/j.ptsp.2005.10.002

[4] Moseley, G.L., Herbert, R.D., Parsons, T., Lucas, S., Van Hilten, J.J. and Marinus, J. (2013) Intense Pain Soon after Wrist Fracture Strongly Predicts Who Will Develop Complex Regional Pain Syndrome: Prospective Cohort Study. The Journal of Pain, $15,1-8$.

[5] Schwartzmann, R.J., Alexander, G.M. and Grothusen, J. (2006) Pathophysiology of Complex Regional Pain Syndrome. Expert Review of Neurotherapeutics, 6, 669-681.

[6] Fernandez-de-las-Penas, C., Ortega-Santiago, R., Ambite-Quesada, S., et al. (2010) Specific Mechanical Pain Hypersensitivity over Peripheral Nerve Trunks in Women with Either Unilateral Epicondylalgia or Carpal Tunnel Syndrome. Journal of Orthopaedic \& Sports Physical Therapy, 40, 751-760.

https://doi.org/10.2519/jospt.2010.3331

[7] Barnhoorn, K.J., Staal, J.B., van Dongen, R.T.M., et al. (2015) Are Pain-Related Fears Mediators for Reducing Disability and Pain in Patients with Complex Regional Pain Syndrome Type 1? An Explorative Analysis on Pain Exposure Physical 
Therapy. PLoS ONE, 10, e0123008. https://doi.org/10.1371/journal.pone.0123008

[8] Walsh, M.T. (2006) Upper Limb Neural Tension Testing and Mobilization: Fact, Fiction, and a Practical Approach. Journal of Hand Therapy, 18, 241-259. https://doi.org/10.1197/j.jht.2005.02.010

[9] Butler, D.S. (1989) Adverse Mechanical Tension in the Nervous System: A Model for Assessment and Treatment. Australian Journal of Physiotherapy, 35, 227-238. https://doi.org/10.1016/S0004-9514(14)60511-0

[10] Butler, D.S. (1991) Mobilisation of the Nervous System. Churchill Livingstone, Toronto, Canada.

[11] Nee, R.J., Jull, G.A., Vicenzino, B. and Coppieters, M.W. (2012) The Validity of Upper-Limb Neurodynamic Tests for Detecting Peripheral Neuropathic Pain. Journal of Orthopaedic \& Sports Physical Therapy, 42, 413-424. https://doi.org/10.2519/jospt.2012.3988

[12] Chu, J., Allen, D.D., Pawlowsky, S. and Smoot, B. (2014) Peripheral Response to Cervical or Thoracic Spinal Manual Therapy: An Evidence-Based Review with Meta Analysis. Journal of Manual and Manipulative Therapy, 22, 220-229.

[13] Fernandez-de-las-Penas, C., Alonso-Blanco, C., Cleland, J.A., Rodriguez-Blanco, C. and Alburquerque-Sendin, F. (2008) Changes in Pressure pain Thresholds over C5-C6 Zygapophyseal Joint after a Cervicothoracic Junction Manipulation in Healthy Subjects. Journal of Manipulative and Physiological Therapeutics, 31, 332-337. https://doi.org/10.1016/j.jmpt.2008.04.006

[14] Salom-Moreno, J., Ortega-Santiago, R., Cleland, J.A., et al. (2014) Immediate Changes in Neck Pain Intensity and Widespread Pressure Pain Sensitivity in Patients with Chronic Bilateral Mechanical Neck Pain: A Randomized Controlled Trial of Thoracic Thrust Manipulation vs Non-Thrust Manipulation. Journal of Manipulative and Physiological Therapeutics, 37, 312-319. https://doi.org/10.1016/j.jmpt.2014.03.003

[15] Bialosky, J.E., Bishop, M.D., Price, D.D., Robinson, M.E. and George, S.Z. (2009) The Mechanisms in Manual Therapy in the Treatment of Musculoskeletal Pain: A Comprehensive Model. Manual Therapy, 14, 531-538. https://doi.org/10.1016/j.math.2008.09.001

[16] Rade, M., Shacklock, M., Rissanen, S.M., et al. (2014) Effect of Glenohumeral Forward Flexion on Upper Limb Myoelectric Activity during Simulated Mills Manipulation; Relations to Peripheral Nerve Biomechanics. BMC Musculoskeletal Disorders, 15, 288-298. https://doi.org/10.1186/1471-2474-15-288

[17] Sahrmann, S.A. (2002) Diagnosis and Treatment of Movement Impairment Syndromes. Mosby, Inc., St. Louis, MO.

[18] Sahrmann, S.A., et al. (2010) Movement System Impairment Syndromes of the Extremities, Cervical and Thoracic Spines. Mosby, Inc., St. Louis, MO.

[19] Nielsen, M., Keefe, F.J., Bennell, K. and Jull, G.A. (2014) Physical Therapist-Delivered Cognitive-Behavioral Therapy: A Qualitative Study of Physical Therapists' Perceptions and Experiences. Physical Therapy, 94, 197-209.

https://doi.org/10.2522/ptj.20130047

[20] Freudenreich, O., Kontos, N. and Querques, J. (2010) The Muddles of Medicine: A Practical, Clinical Addendum to the Biopsychosocial Model. Psychosomatics, 51, 365-369. https://doi.org/10.1016/S0033-3182(10)70717-9

[21] DeLitto, A., George, S.Z., van Dillen, L., et al. (2012) Low Back Pain: Clinical Practice Guidelines Linked to the International Classification of Functioning, Disability, and Health from the Orthopaedic Section of the American Physical Therapy Asso- 
ciation. Journal of Orthopaedic \& Sports Physical Therapy, 42, A1-A57. https://doi.org/10.2519/jospt.2012.42.4.a1

[22] Inrig, T., Amey, B., Borthwick, C. and Beaton, D. (2012) Validity and Reliability of Fear-Avoidance Beliefs Questionnaire (FABQ) in Workers with Upper Extremity Injuries. Journal of Occupational Rehabilitation, 22, 59-70.

https://doi.org/10.1007/s10926-011-9323-3

[23] Mintken, P.E., Cleland, J.A., Whitman, J.M. and George, S.Z. (2010) Psychometric Properties of the Fear-Avoidance Beliefs Questionnaire and Tampa Scale of Kinesiophobia in Patients with Shoulder Pain. Archives of Physical Medicine and Rehabilitation, 91, 1128-1136. https://doi.org/10.1016/j.apmr.2010.04.009

[24] Polson, K., Reid, D., McNair, P.J. and Larmer, P. (2010) Responsiveness, Minimal Importance Difference and Minimal Detectable Change Scores of the Shortened Disability Arm Shoulder Hand (QuickDASH) Questionnaire. Manual Therapy, 15, 404-407. https://doi.org/10.1016/j.math.2010.03.008

[25] Franchignoni, F., Vercelli, S., Giordano, A., et al. (2014) Minimal Clinically Important Difference of the Disabilities of the Arm, Shoulder and Hand Outcome Measure (DASH) and Its Shortened Version (QuickDASH). Journal of Orthopaedic \& Sports Physical Therapy, 44, 30-39. https://doi.org/10.2519/jospt.2014.4893

[26] (2015) Guide to Physical Therapist Practice 3.0. http://guidetoptpractice.apta.org/content/current

[27] Kahl, C. and Cleland, J.A. (2005) Visual Analogue Scale, Numeric Pain Rating Scale and the McGill Pain Questionnaire: An Overview of Psychometric Properties. Physical Therapy Reviews, 10, 123-128.

[28] Macioni, V. (2013) Reliability of the Standard Goniometry and Diagrammatic Recording of Finger Joint Angles: A Comparative Study with Healthy Subjects and Non-Professional Raters. BMC Musculoskeletal Disorders, 14, 1-11.

[29] Kroon, P. and Boucher, B. (2014) Functional Approach to the Treatment of TFCC Problems: Extension Radial Deviation Syndrome of the Wrist. Paper presented at: American Academy of Orthopaedic Manual Physical Therapists, Texas State University, San Marcos, TX, October 2014.

[30] Staes, F.F., Banks, K.J., De Smet, L., Daniels, K.J. and Carels, P. (2009) Reliability of Accessory Motion Testing at the Carpal Joints. Manual Therapy, 14, 292-298. https://doi.org/10.1016/j.math.2008.04.001

[31] van de Pol, R.J., van Trijffel, E. and Lucas, C. (2010) Inter-Rater Reliability for Measurement of Passive Physiological Range of Motion of Upper Extremity Joints Is Better If Instruments Are Used: A Systematic Review. Journal of Physiotherapy, 56, 7-17. https://doi.org/10.1016/S1836-9553(10)70049-7

[32] Kendall, F.P., McCreary, E.K., Provance, P.G., Rodgers, M.M. and Romani, W.A. (2005) Muscles Testing and Function with Posture and Pain. 5th Edition, Lippincott Williams \& Wilkins, Baltimore, MD.

[33] Trampisch, U.S., Franke, J., Jedamzik, N., Hinrichs, T. and Platen, P. (2012) Optimal Jamar Dynamometer Handle Position to Assess Maximal Isometric Hand Grip Strength in Epidemiological Studies. Journal of Hand Surgery, 37, 2368-2373. https://doi.org/10.1016/j.jhsa.2012.08.014

[34] Harlinger, W.V., Blalock, L. and Merrit, J.L. (2015) Upper Limb Strength: Study Providing Normative Data for a Clinical Handheld Dynamometer. PMRJ, 7, 135140. https://doi.org/10.1016/j.pmrj.2014.09.007

[35] Lifchez, S.D., Means Jr., K.R., Dunn, R.E. and Williams, E.H. (2010) Intra- and Inter-Examiner Variability in Performing Tinel's Test. Journal of Hand Surgery, 35, 
212-216. https://doi.org/10.1016/j.jhsa.2009.11.006

[36] Oskouei, A.E., Talebi, G.A., Shakouri, S.K. and Ghabili, K. (2014) Effects of Neuromobilization Maneuver on Clinical and Electrophysiological Measures of Patients with Carpal tunnel Syndrome. Journal of Physical Therapy Science, 26, 1017-1022. https://doi.org/10.1589/jpts.26.1017

[37] Jette, A.M. (2006) Toward a Common Language for Function, Disability, and Health. Physical Therapy, 86, 726-734.

[38] Atkinson, H.L. and Nixon-Cave, K. (2011) A Tool for Clinical Reasoning and Reflection Using the International Classification of Functioning, Disability and Health (ICF) Framework and Patient Management Model. Physical Therapy, 91, 416-430. https://doi.org/10.2522/ptj.20090226

[39] Sullivan, K.J. and Cen, S.Y. (2011) Model of Disablement and Recovery: Knowledge Translation in Rehabilitation Research and Practice. Physical Therapy, 91, 18921904. https://doi.org/10.2522/ptj.20110003

[40] Childs, J.D., Piva, S.R. and Fritz, J.M. (2005) Responsiveness in Numeric Pain Rating Scale in Patients with Low Back Pain. Spine, 30, 1331-1334.

https://doi.org/10.1097/01.brs.0000164099.92112.29

[41] Maitland, G. (2007) Maitland's Peripheral Manipulation: Management of Neuromusculoskeletal Disorders. Vol. 2, 5th Edition, Elsevier Health Sciences, Rotherham, UK.

[42] Coppieters, M.W. and Butler, D.S. (2008) Do "Sliders" Slide and "Tensioners" Tension? An Analysis of Neurodynamic Techniques and Considerations Regarding Their Applications. Manual Therapy, 13, 213-221. https://doi.org/10.1016/j.math.2006.12.008

[43] Coppieters, M.W., Hough, A.D. and Dilley, A. (2009) Different Nerve-Gliding Exercises Induce Different Magnitudes of Median Nerve Longitudinal Excursion: An in Vivo Study Using Dynamic Ultrasound Imaging. Journal of Orthopaedic \& Sports Physical Therapy, 39, 164-171. https://doi.org/10.2519/jospt.2009.2913

[44] Jull, G.A., O’Leary, S.P. and Falla, D.L. (2008) Clinical Assessment of the Deep Cervical Flexor Muscles: The Craniocervical Flexion Test. Journal of Manipulative and Physiological Therapeutics, 31, 525-533. https://doi.org/10.1016/j.jmpt.2008.08.003

[45] Falla, D., O’Leary, S., Farina, D. and Jull, G. (2011) Association between Intensity of Pain and Impairment in Onset and Activation of Cervical Deep Neck Flexors in Patients with Persistent with Neck Pain. The Clinical Journal of Pain, 27, 309-314. https://doi.org/10.1097/AJP.0b013e31820212cf

[46] Andersen, C.H., Zebis, M.K., Saervoll, C., et al. (2012) Scapular Muscle Activity from Selected Strengthening Exercises Performed at Low and High Intensities. Journal of Strength and Conditioning Research, 26, 2408-2416. https://doi.org/10.1519/JSC.0b013e31823f8d24

[47] Elven, M., Hochwalder, J., Dean, E. and Soderlund, A. (2015) A Clinical Reasoning Model Focused on Clients' Behavior Change with Reference to Physiotherapists: Its Multiphase Development and Validation. Physiotherapy Theory and Practice, 31, 231-243.

[48] George, S.Z. and Stryker, S.E. (2011) Fear-Avoidance Beliefs and Clinical Outcomes for Patients Seeking Outpatient Physical Therapy for Musculoskeletal Pain Conditions. Journal of Orthopaedic \& Sports Physical Therapy, 41, 249-259. https://doi.org/10.2519/jospt.2011.3488

[49] Swinkles-Meewisse, E.J.C.M., Swinkles, R.A.H.M., Verbeek, A.L.M., Vlaeyen, J.W.S. and Oostendorp, R.A.B. (2003) Psychometric Properties of the Tampa Scale for Ki- 
nesiophobia and the Fear-Avoidance Beliefs Questionnaire in Acute Low Back Pain. Manual Therapy, 8, 29-36. https://doi.org/10.1054/math.2002.0484

[50] Mathews, M. (2014) Multimodal Treatment of Pain. Neurosurgery Clinics of North America, 25, 803-808. https://doi.org/10.1016/j.nec.2014.07.005

[51] Sahrmann, S.A. (2014) The Human Movement System: Our Professional Identity. Physical Therapy, 94, 1034-1042. https://doi.org/10.2522/ptj.20130319

[52] Scheets, P.L., Sahrmann, S.A. and Norton, B.J. (2007) Use of Movement System Diagnoses in the Management of Patients with Neuromuscular Conditions: A Multiple-Patient Case Report. Physical Therapy, 87, 654-669.

https://doi.org/10.2522/ptj.20050349

Submit or recommend next manuscript to OALib Journal and we will provide best service for you:

- Publication frequency: Monthly

- 9 subject areas of science, technology and medicine

- Fair and rigorous peer-review system

- Fast publication process

- Article promotion in various social networking sites (LinkedIn, Facebook, Twitter, etc.)

- Maximum dissemination of your research work

Submit Your Paper Online: Click Here to Submit

Or Contact service@oalib.com 